Bangladesh Journal of Neuroscience 2017; Vol. 33 (2): 55-62

\title{
Association between Modifiable Risk Factors and Stroke Recurrence in Patients with First Ever Ischemic Stroke
}

\author{
HASSAN S ${ }^{1}$, ISLAM MR², RAHMAN HZ ${ }^{3}$
}

\begin{abstract}
:
Background: Stroke is the third leading cause of death in adult population throughout the world and is the most common cause of severe adult physical disability. It is increasing at an alarming rate in Asia including Bangladesh. The effect of recurrent stroke is devastating on patient as it is the main reason of mortality and morbidity among patients Methods: A longitudinal, observational study was conducted from April 2018 to October 2018 in the department of Neurology, Bangabandhu Sheikh Mujib Medical University, Dhaka. All the patients of first ever ischemic stroke confirmed by neuroimaging (CT scan of head / MRI of brain), meeting the inclusion and exclusion criteria were included in the study. Our study was performed with sixty stroke patients. We followed up patient up to 90 days and observed for stroke recurrence. Results: Present study showed among the 60 stroke patients, only $4(6.67 \%)$ suffered from stroke recurrence within 3 months. In our study, uncontrolled systolic blood pressure $(p=0.04)$, uncontrolled diastolic blood pressure $(p=0.027)$, dyslipidaemia $(p=0.001)$, smoking $(p=0.0003)$ and antiplatelet discontinuation ( $p=0.0001$ ) were significantly associated with stroke recurrence whereas uncontrolled diabetes mellitus $(p=0.46)$ and presence of atrial fibrillation $(p=0.057)$ had no significant association. Conclusion: Smoking, hypercholesterolemia, uncontrolled systolic \&/or diastolic blood pressure and discontinuation of antiplatelet therapy were significantly associated with stroke recurrence in this population. Therefore, early identification and control of these risk factors are essential to prevent recurrent stroke, thereby decrease morbidity and mortality.
\end{abstract}

Key words: Stroke, Cerebral infarct, Risk factors, Recurrence, Complications etc.

\section{Introduction:}

Stroke is a leading cause of death and disability worldwide. There are approximately 795,000 new or recurrent strokes annually in the United States $(610,000$ being first events and 185,000 being recurrent events) ${ }^{1}$. Some $88 \%$ of these strokes are ischemic and $8 \%$ to $12 \%$ of ischemic strokes result in death within 30 days. By 2020, 19 of 25 million annual stroke deaths will be in developing countries $^{2}$.

Stroke recurrence is a major problem around the world, leading to permanent and more severe disability among patients. It has been reported that recurrence rate is approximately between $15-40 \%$ within five years after a first episode. The maximum incidence of recurrent stroke is in the first 30 days after initial stroke ${ }^{3}$. Recurrence is frequent and is a major contributor to stroke morbidity and mortality. The immediate period after a stroke carries the greatest risk for recurrence. In the Stroke Data Bank, of 1273 patients with infarcts, $3.3 \%$ had an early recurrence within 30 days. Nearly one third of the recurrent strokes in 2 years of follow-up occurred within the first 30 days. Early stroke recurrence increased motor weakness scores, early mortality, and duration of hospital stay. The predictors of first recurrent stroke were advanced age, hemorrhagic index stroke and diabetes mellitus. In the Northern Manhattan Stroke Study stroke recurrence was frequent, with $25 \%$ suffering a recurrent stroke by 5 years. Moreover, mortality after a recurrent stroke was greater than after the index stroke ${ }^{4}$.

1. Dr. Shahadat Hassan, OSD, DGHS, Ministry of Health and Family Welfare, Dhaka, Bangladesh.

2. Dr. Md Rafiqul Islam. Professor, Department of Neurology, BSMMU, Dhaka, Bangladesh.

3. Dr. Hasan Zahidur Rahman, Professor, Department of Neurology, BSMMU, Dhaka, Bangladesh. 
The prevalence of stroke is increasing at an alarming rate in Asia including Bangladesh. Increasing portion of aging population and escalating risk factors such as hypertension, diabetes, tobacco abuse, unhealthy diet, obesity and physical inactivity contribute to the development of atherosclerosis and ultimately stroke ${ }^{5}$. It is very much important to find out the risk factors for recurrent stroke and to modify these factors as much as possible. Unfortunately, there is scanty data regarding recurrent stroke in Bangladesh. Therefore, this study intends to find out the impact of controlling modifiable risk factors and recurrence rate after first-ever ischemic stroke in a tertiary care hospital in Bangladesh. The findings of this study will help the physicians in this country as well as other countries of the world to predict the risk of recurrence in ischemic stroke patients and take necessary steps to modify the risk factors. It will also help the policy makers to allocate resources in appropriate places, which will help in decreasing the rate of mortality and disability in stroke patients.

\section{Materials and methods:}

This was a longitudinal, observational study conducted from April 2018 to October 2018 in the Department of Neurology, Bangabandhu Sheikh Mujib Medical University, Dhaka. All the patients of first ever ischemic stroke confirmed by neuroimaging (CT scan of head / MRI of brain), meeting the inclusion and exclusion criteria were included in the study. We followed up the patients up to 90 days and observed for stroke recurrence. Assuming a recurrence rate of $25 \%(95 \% \mathrm{Cl}, 7.2-$ 9.0), sample size should have been $106^{3}$. But due to time and resource constraints, data was taken from 60 subjects in our study. Purposive sampling method was followed. Inclusion criteria waspatients of first ever ischemic stroke with age 18 to 80 years, and the patient or patient's legal guardian willing to participate. Exclusion criteria were-age less than 18 years or more than 80 years, ischemic stroke in whom there is evidence of previous stroke, hemorrhagic stroke, silent cerebral infarct, and patient or patient's legal guardian not willing to take part in the study. After ethical clearance from Institutional Review Board (IRB), patients were selected following the mentioned inclusion and exclusion criteria. Patients in whom 15 days have crossed after index stroke were not taken and evaluated as sample. Informed written consent was taken from each patient or his/her attendant. Proper history was taken, physical and neurological examination was done, and all relevant investigations were completed including a CT or MRI of brain. All the biochemical and hematological tests were done within 15 days of index stroke. Samples were collected with aseptic precaution and sent to respective laboratories of BSMMU (i.e Biochemistry, Pathology and Immunology labs). Hypertension, diabetes mellitus (DM), and hyperlipidemia were diagnosed according to established criteria. The included patients were followed up at 4 weekly intervals after index stroke. Modifiable risk factors for stroke were reevaluated at each follow-up upto 90 days. Previously diagnosed hypertension was regarded as controlled when blood pressure was lower than $130 / 80 \mathrm{~mm} \mathrm{Hg}$. DM was regarded as controlled when fasting serum glucose level was lower than $7.2 \mathrm{mmol} / \mathrm{L}, 2 \mathrm{ABF}$ was lower than $10 \mathrm{mmol} / \mathrm{ml}$ and $\mathrm{HbA} 1 \mathrm{c}$ was less than $7 \%$ (American Diabetes Association 2018). Hyperlipidemia was regarded as controlled LDL-C level $\leq 100 \mathrm{mg} / \mathrm{dL}$. Patients with atrial fibrillation (AF) who were on anticoagulation were regarded as adequately anticoagulated when the international normalized ratio (INR) was kept in the range of 2.0-3.0. Patients were considered as being under appropriate antiplatelet therapy when they received aspirin at a daily dose between $75 \mathrm{mg}$, or clopidogrel at $75 \mathrm{mg}$, after index stroke. Ischemic stroke was confirmed by CT scan or MRI.

Data collection sheet was filled-up by face to face interview. Patients were followed up every four weekly after the first visit. Blood glucose, lipid profile, ECG, adherence to antiplatelet therapy and smoking habit were followed up and recorded in a semistructured data collection sheet. Statistical analysis was conducted using a software package, SPSS for Windows, Version 21.0 (SPSS Inc., Chicago, II, USA). Approval from the Institutional Review Board (IRB) of BSMMU was obtained prior to the commencement of this study. The aim and objective of the study along with its procedure, risk and benefits were explained to the respondents in easily 
understandable local language and informed written consent was taken from each. It was assured that all information and record will be kept confidential.

\section{Results:}

Total 83 patients were included in our study. Of them 23 patients lost from follow-up. Data was collected from the remaining 60 patients. Of the 60 patients included in the study, most $17(28.33 \%)$ belonged to the age group 51-60 years, followed by $13(21.67 \%)$ patients in the age group $61-70$ years. Eleven (18.33\%) patients were from 41-50 year age, $8(13.33 \%)$ in $71-80$ years, $7(11.67 \%)$ in $31-40$ years and only $4(6.67 \%)$ patients were from 18-30 year age group. Mean age of the respondents was $53.04 \pm 16.72$ years (Figure-1).

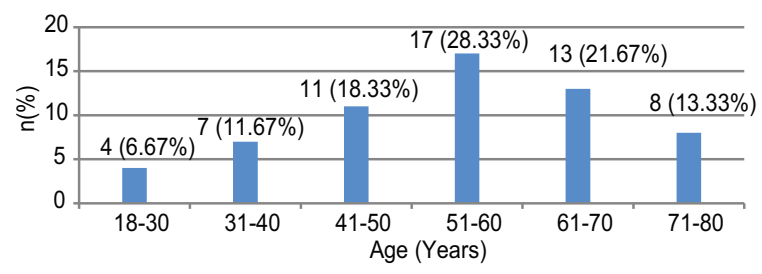

Fig.-1: Age group distribution of the study subjects $(N=60)$

Thirty-eight $(63.33 \%)$ of the study subjects were male. Only 22 (36.67\%) were of female gender.

Most $17(28.33 \%)$ of the respondents were retired, followed by service holder $12(20.0 \%)$ and business $11(18.33 \%)$. Hypertension was the most common risk factor, followed by dyslipidemia, diabetes mellitus, smoking, previous, and ischemic heart disease for ischemic stroke patients.

\section{Table-I}

Distribution of study population by risk factors* $(N=60)$

\begin{tabular}{|c|c|}
\hline Risk factors & $\mathrm{n}(\%)$ \\
\hline DM & 35 (59.5) \\
\hline HTN & $51(83.5)$ \\
\hline Dyslipidaemia & 49 (81.0) \\
\hline Family history & $9(16.7)$ \\
\hline Smoking & $34(57.1)$ \\
\hline Drug Abuse & $1(1.67 \%)$ \\
\hline Alcoholism & $1(1.67 \%)$ \\
\hline OCP & $1(1.67 \%)$ \\
\hline \multicolumn{2}{|l|}{ Heart disease } \\
\hline - Ischemia/Old MI & $39(65.0 \%)$ \\
\hline - Atrial fibrillation & $3(5.0 \%)$ \\
\hline
\end{tabular}

*Multiple response elicited
Regarding the baseline clinical parameters of the study subjects, mean pulse rate was $81 \pm 17.64 \mathrm{~b} /$ min, mean systolic and diastolic blood pressures were $157.13 \pm 22.06$ and $98.35 \pm 13.79 \mathrm{~mm} \mathrm{Hg}$ respectively. Irregular pulse was found in $5(8.33 \%)$ patients, carotid bruit in $7(11.67 \%)$ patients, and cardiac murmur in $4(6.67 \%)$ patients (Table-II).

\section{Table-II}

Baseline clinical parameters of the study subjects at presentation $(N=60)$

\begin{tabular}{|c|c|c|}
\hline \multicolumn{3}{|l|}{ Parameter } \\
\hline Pulse rate(b/min) & (Mean \pm SD) & $81 \pm 17.64$ \\
\hline Systolic BP (mm Hg) & (Mean \pm SD) & $157.13 \pm 22.06$ \\
\hline Diastolic BP (mm Hg) & (Mean $\pm S D)$ & $98.35 \pm 13.79$ \\
\hline Temperature $\left({ }^{0} \mathrm{~F}\right)$ & (Mean $\pm S D$ ) & $99.8 \pm 2.26$ \\
\hline \multicolumn{3}{|l|}{ Irregular pulse } \\
\hline - Present & $n(\%)$ & $5(8.33 \%)$ \\
\hline - Absent & $\mathrm{n}(\%)$ & $55(91.67 \%)$ \\
\hline \multicolumn{3}{|l|}{ Carotid Bruit } \\
\hline - Present & $n(\%)$ & $7(11.67 \%)$ \\
\hline - Absent & $\mathrm{n}(\%)$ & $53(88.33 \%)$ \\
\hline \multicolumn{3}{|l|}{ Cardiac murmur } \\
\hline - Present & $n(\%)$ & $4(6.67 \%)$ \\
\hline - Absent & $n(\%)$ & $56(93.33 \%)$ \\
\hline
\end{tabular}

Table-III

Baseline biochemical and hematological parameters of study subjects $(N=60)$

\begin{tabular}{|c|c|}
\hline Investigation & Mean \pm SD \\
\hline$\overline{\mathrm{Hb} \%}(\mathrm{gm} / \mathrm{dL})$ & $12.3 \pm 2.27$ \\
\hline WBC count (per $\mathrm{mm}^{3}$ ) & $8340 \pm 2533$ \\
\hline ESR (mm in $1^{\text {st }}$ hour) & $28.2 \pm 13.4$ \\
\hline Fasting blood glucose (mmol/L) & $9.8 \pm 3.71$ \\
\hline $\mathrm{HbA}_{1 \mathrm{c}}(\%)$ & $8.44 \pm 2.88$ \\
\hline Blood urea $(\mathrm{mg} / \mathrm{dL})$ & $26.4 \pm 9.31$ \\
\hline Serum creatinine (mg/dL) & $0.93 \pm 0.17$ \\
\hline Serum ALT (u/L) & $48.3 \pm 18.8$ \\
\hline \multicolumn{2}{|l|}{$\mathrm{ECG}^{*}$} \\
\hline - Ischemia/Old MI(\%) & $39(65.0 \%)$ \\
\hline - Atrial fibrillation(\%) & $3(5.0 \%)$ \\
\hline \multicolumn{2}{|l|}{ Echocardiogram* } \\
\hline - RWMA & $16(26.67 \%)$ \\
\hline - Valvular heart disease $\mathrm{n}(\%)$ & $2(3.33 \%)$ \\
\hline
\end{tabular}

The mean $\mathrm{Hb} \%$ was $12.3 \pm 2.27 \mathrm{gm} / \mathrm{dL}$, mean total WBC count was $8340 \pm 2533$ per mm3, ESR $28.2 \pm 13.4 \mathrm{~mm}$ in $1 \mathrm{st}$ hour, mean fasting blood 
glucose9.8 $\pm 3.71 \mathrm{mmol} / \mathrm{L}, \mathrm{HbA} 1 \mathrm{c} 8.44 \pm 2.88 \%$, blood urea26.4 $\pm 9.31 \mathrm{mg} / \mathrm{dL}$, serum creatinine $0.93 \pm 0.17$ $\mathrm{mg} / \mathrm{dL}$, serum ALT 48.3 $\pm 18.8 \mathrm{u} / \mathrm{L}$ (Table-III).

Regarding neurological deficit, 57 (95.0\%) patients had hemiplegia, $43(71.67 \%)$ had speech difficulty, $37(61.67 \%)$ had facial weakness, $21(35.0 \%)$ had unconsciousness, $11(18.33 \%)$ had swallowing difficulty, $11(18.33 \%)$ had vertigo, $8(13.33 \%)$ had ataxia and $3(5.0 \%)$ had nystagmus. Of the 60 study subjects, most $(48.33 \%)$ had large vessel atherosclerosis. Thirteen $(21.67 \%)$ had stroke due to undetermined etiologies, $11(18.33 \%)$ suffered from small artery disease, and only $5(8.33 \%)$ had cardioembolic stroke (Table-IV).

\section{Table-IV}

Type of stroke at presentation according to TOAST classification $(N=60)$

\begin{tabular}{lc}
\hline Stroke subtype & $\mathrm{n}(\%)$ \\
\hline Large vessel atherosclerosis & $29(48.33 \%)$ \\
Cardioembolic & $5(8.33 \%)$ \\
Small artery disease & $11(18.33 \%)$ \\
Other determined etiologies & $2(3.33 \%)$ \\
Undetermined etiologies & $13(21.67 \%)$ \\
\hline
\end{tabular}

Most $54(90.0 \%)$ strokes involved the middle cerebral artery (ACA) territory. Five $(8.33 \%)$ were in posterior cerebral artery territory, and only $1(1.67 \%)$ in anterior cerebral artery territory (Figure-2).

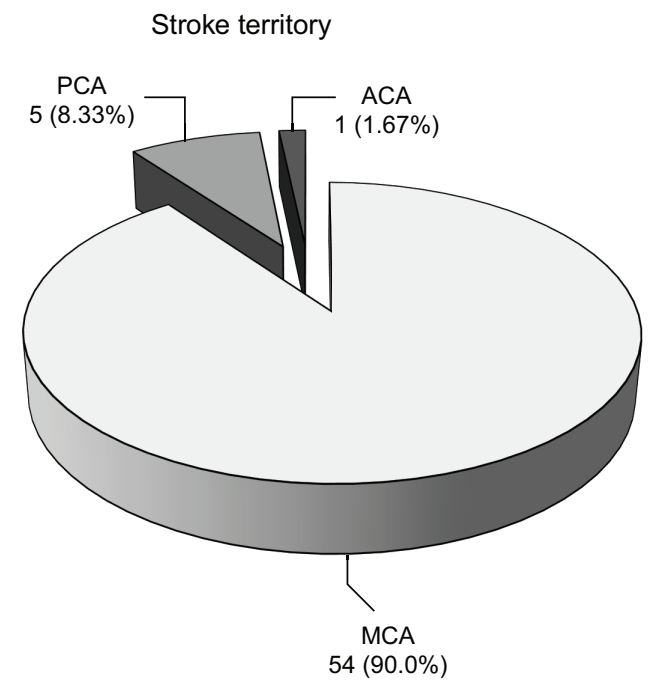

Fig.-2: Distribution of study subjects by vascular territory $(N=60)$
According to NIHSS stroke scale, majority $(61.6 \%)$ of the study subjects were of moderate severity. Only $3(5 \%)$ were suffering from severe stroke. Among the 60 stroke patients, only $(6.67 \%)$ suffered from stroke recurrence within 3 months (Figure-3).

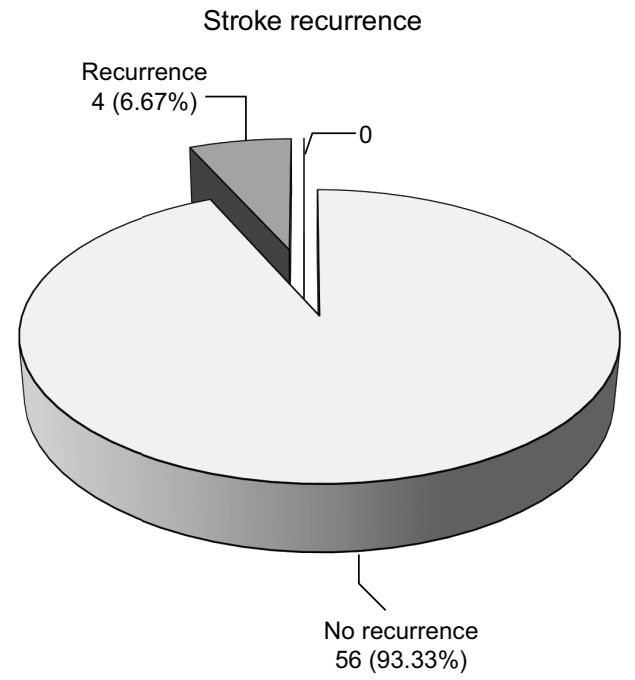

Fig.-3: Recurrence of stroke within 3 months in the study subjects $(N=60)$

Table-V

Association of control of systolic BP with stroke recurrence $(N=60)$

\begin{tabular}{lccc}
\hline & $\begin{array}{c}\text { Stroke } \\
\text { recurrence }\end{array}$ & $\begin{array}{c}\text { No } \\
\text { recurrence }\end{array}$ & P value \\
\hline SBP controlled & 1 & 41 & 0.04 \\
SBP uncontrolled & 3 & 15 & \\
\hline Total & 4 & 56 & \\
\hline
\end{tabular}

Derived by $\chi^{2}$ test. $\chi^{2}$ value 4.1327.df 1 .

Table-XI shows that of the 4 patients with recurrent stroke, 3 had uncontrolled systolic BP, 3 had uncontrolled diastolic BP, 2 had uncontrolled diabetes, 3 had LDL>100 mg/dl, one had atrial fibrillation, 2 patients continued smoking and 3 patients discontinued antiplatelet therapy. 
Table-VI

Risk factor status of subjects with recurrent stroke $(n=4)$

\begin{tabular}{lcccc}
\hline Variables & Case-1 & Case-2 & Case-3 & Case-4 \\
\hline Age (Years) & 60 & 74 & 65 & 60 \\
Sex & Male & Female & Male & Male \\
Date of First stroke & 05-08-2018 & $24-06-2018$ & $20-07-2018$ & $22-07-2018$ \\
Date of Recurrent stroke & $25-08-2018$ & $01-09-2018$ & $28-08-2018$ & $06-08-2018$ \\
Hypertension & Yes & Yes & Yes & Yes \\
Systolic BP & Uncontrolled & Uncontrolled & Uncontrolled & Controlled \\
Diastolic BP & Controlled & Uncontrolled & Uncontrolled & Uncontrolled \\
DM & No & Yes & No & Yes \\
Glycemic status & Controlled & Uncontrolled & Controlled & Uncontrolled \\
Dyslipidemia (LDL>100 mg/dl) & No & Yes & Yes & Yes \\
Atrial fibrillation & Yes & No & No & No \\
Smoking status & Yes & No & No & Yes \\
Adherence to antiplatelet/ & Anticoagulant & No & No & No \\
anticoagulant therapy & & & & \\
\hline
\end{tabular}

\section{Discussion:}

In the present study we intended to find out the frequency of stroke recurrence within 3 months of first ever ischemic stroke and to find out the association of modifiable risk factor control with stroke recurrence. This longitudinal observational study was done on 60 stroke patients presenting to the outpatient and inpatient departments of BSMMU over the period of April to October 2018. Total 60 patients were included in the study after their first ever ischemic stroke. Out of the 60 patients included in the study, most 17 (28.33\%) belonged to the age group 51-60 years, followed by $13(21.67 \%)$ patients in the age group $61-70$ years. Eleven (18.33\%) patients were from 41-50 year age, $8(13.33 \%)$ in $71-80$ years, $7(11.67 \%)$ in $31-40$ years and only $4(6.67 \%)$ patients were from 18-30 year age group. Mean age of the respondents was $53.04 \pm 16.72$ years. This result is consistent with a previous study, where mean age was $55.4( \pm 10.4)$ in a population of 1155 first ever ischemic stroke patients which was done on an Asian population of Philippines ${ }^{3}$. But in The Northern Manhattan Study the mean age was much higher $(69.7 \pm 12.7 \text { years })^{4}$. In a cross sectional study carried out in 100 patients of stroke, most of the patients suffering from stroke were male and most of them were between 51-70 years of age ${ }^{9}$.
Uddin et al. $(2008)^{10}$ and Idicula et al. (2009) ${ }^{11}$ showed that ischemic stroke was more common in male than female. Hannan et al. (2001) ${ }^{12}$ showed that male to female ratio was 2.53:1.

This study shows that among the baseline clinical parameters, mean pulse rate was $81 \pm 17.64 \mathrm{~b} / \mathrm{min}$, mean systolic and diastolic blood pressures were $157.13 \pm 22.06$ and $98.35 \pm 13.79 \mathrm{~mm} \mathrm{Hg}$ respectively. Irregular pulse was found in $5(8.33 \%)$ patients, carotid bruit in $7(11.67 \%)$ patients, and cardiac murmur in $4(6.67 \%)$ patients. In the Framingham Study 5070 participants were followed up for 34 years. The age adjusted incidence of stroke was more than doubled in the presence of coronary heart disease $(p<0.001)$ and more than trebled in the presence of hypertension $(p<0.001)$, compared with subjects free of these conditions. There was a more than fourfold excess of stroke in subjects with cardiac failure $(p<0.001)$ and a near fivefold excess when atrial fibrillation was present $(p<0.001)$. Among this biochemical findings it is obvious that mean fasting blood glucose was high $(9.8 \pm 3.71 \mathrm{mmol} / \mathrm{L})$. It is also being seen in postprandial blood glucose. HbA1c $8.44 \pm 2.88 \%$ shows that most patients were in the diabetic range .Many land mark studies showed the casual relationship between diabetes and ischemic stroke .In patients with type 2 diabetes the risk of diabetic 
complications was strongly associated with previous hyperglycaemia ${ }^{13}$. On initial neurologic deficits of study subjects at presentation. fifty-seven $(95.0 \%)$ patients had hemiplegia, $43(71.67 \%)$ had speech difficulty, $37(61.67 \%)$ had facial weakness, $21(35.0 \%)$ had unconsciousness, $11(18.33 \%)$ had swallowing difficulty, 11(18.33\%) had vertigo, 8 $(13.33 \%)$ had ataxia and $3(5.0 \%)$ had nystagmus. Among the findings hemiplegia and speech disturbance are the most common neurological deficits among patients, which was followed by unconsciousness and other disturbances. These findings are common and readily bring the patient to the attention of physician and medical service. In the study by Siddique et al. (2009), most of the patients with ischemic stroke presented with right sided hemiparesis $(51.25 \%)$. Dysarthria was present in $48(60 \%)$ cases, motor dysphasia in $47(58.75 \%)$, sensory dysphasia in $1(1.25 \%)$, impaired consciousness in 43(53.75\%), headache in $43.75 \%$ (35) patients, vomiting in $40 \%$ (32) and nystagmus in $3\left(3.75 \%\right.$ ) cases of ischemic stroke ${ }^{14}$. Of the 60 study subjects, most $(48.33 \%)$ had large vessel atherosclerosis. Thirteen $(21.67 \%)$ had stroke due to undetermined etiologies, 11 (18.33\%) suffered from small artery disease, and only 5 $(8.33 \%)$ had cardioembolic stroke. In the study by Karapanayiotides et al. (2004), 33\% were due to large vessel atherosclerosis, $21 \%$ cardioembolic, $17 \%$ small vessel disease, $16 \%$ due to other causes and $13 \%$ of undetermined etiology 15 . Nedeltchev et al. (2004) found that most strokes were caused by cardiac embolism and cervical artery dissection (24\%), whereas only $9 \%$ and $4 \%$ resulted from small vessel disease and large artery atherosclerosis, respectively. Thirty percent were due to other determined etiology ${ }^{16}$.

In this study, most $54(90.0 \%)$ strokes involved the middle cerebral artery (ACA) territory. Five (8.33\%) were in posterior cerebral artery territory, and only $1(1.67 \%)$ in anterior cerebral artery territory. Nedeltchev et al. (2004) found that of the total 203 patients with stroke, $31(15.27 \%)$ had total anterior circulation stroke, $80(39.40 \%)$ had partialanterior circulation stroke, $38(18.71 \%)$ had lacunar stroke and $34(16.73 \%)$ had posterior circulation stroke ${ }^{16}$. In our study among the 60 stroke patients, only 4
$(6.67 \%)$ suffered from stroke recurrence after 3 months. Buenaflor et al. (2017) found that among the 1155 first onset ischemic stroke patients, $12.8 \%$ had a second ischemic event within the next year, with an average of $8 \%$ annual risk for stroke recurrence over three years ${ }^{3}$.

A study done by Leoo et al.(2007) in Sweden found that among the 889 patients who had recurrent stroke, the most frequent risk factor was hypertension (75\%) followed by hyperlipidemia (56\%), 37\% had ischemic heart disease, $29 \%$ atrial fibrillation and $24 \%$ diabetes mellitus. Thirteen percent were current smokers and $11 \%$ were classified as obese ${ }^{17}$. The findings of this study is comparable to our study. In a study by Moroney et al. (1998) it was found that among vascular risk factors, there was a higher rate of recurrence among patients with hypertension, consistent cigarette use, and alcohol consumption but those differences failed to reach statistical significance. Among cardiac conditions, there was a trend toward a higher rate of early recurrence in patients with atrial fibrillation, but a significant effect was not found for other cardiac conditions ${ }^{18}$. In a similar hospital based retrospective study by $\mathrm{Fu}$ at el. (2016) in China, it was found that recurrent stroke in older men included previous history of myocardial infarction (OR 6.761; 95\% Cl 1.03-44.371), ischemic stroke or transient ischemic attack (OR, 2.496; $95 \% \mathrm{Cl}, 1.567-3.976)$, diabetes mellitus (OR, 1.986; 95\% Cl, 1.223-3.227), and coronary atherosclerotic disease (OR, 1.733; 95\% Cl, 1.0102.974). In young men, hypertension (OR, 1.709; $95 \% \mathrm{Cl}, 1.104-2.645)$, coronary atherosclerotic heart disease (OR, 1.812; 95\% Cl, 1.129-2.911), and previous history of ischemic stroke or transient ischemic attack (OR, 2.317; 95\% Cl, 1.580-3.397) were independent risk factors of recurrent strokes ${ }^{19}$. As we did not evaluate non modifiable risk factors it was similar to our study in comparison.

\section{Limitations:}

Every study has some limitations. Our study was done in short period, with a small sample size. Study population were enrolled from only one center hence it may not represent the whole 
population of the country. Also, the method of sampling was purposive, i.e. non-random sampling, which may affect the findings.

\section{Recommendations:}

We recommend that risk factors for recurrent stroke should be identified early and interventions done for their control to prevent recurrence. Further multi-centered prospective cohort study with large sample size and longer period should be conducted. Stroke patients and caregivers should be made aware of the importance of risk factor modification.

\section{Conclusion:}

This longitudinal observational study showed that chance of stroke recurrence within 3 months of first ever ischemic stroke is $6.67 \%$ in a tertiary care hospital. Smoking, hypercholesterolemia, uncontrolled systolic \&/or diastolic blood pressure and discontinuation of antiplatelet therapy were significantly associated with stroke recurrence in this population, whereas there was no significant association with uncontrolled diabetes and atrial fibrillation. Therefore, early identification and control of these risk factors are essential to prevent recurrent stroke, thereby decrease morbidity and mortality.

\section{References:}

1. Go AS, Mozaffarian D, Roger VL., Benjamin EJ, Berry JD, Blaha MJ et al. Executive summary: Heart disease and stroke statistics-2014 update: A report from the American Heart Association. Circulation 2014; 129: 399-410.

2. Lemogoum D, Degaute JP, Bovet P. Stroke prevention, treatment, and rehabilitation in Sub-Saharan Africa. Am J Prev Med 2005;29: 95-101.

3. Buenaûor FGB, Navarro JC, Lara KJA, Venketasubramanian N. Recurrence Rate of Ischemic Stroke: A Single Center Experience. Austin J Cerebrovasc Dis \& Stroke 2017; 4 (2): id1057.

4. Dhamoon MS, Sciacca RR, Rundek T, Sacco RL, Elkind MSV. Recurrent stroke and cardiac risks after first ischemic stroke: The Northern Manhattan Study. Neurology 2006; 66: 641-646.

5. Das S, Chakrabarti K, Patnaek M, Roul L, Mohanti J, Sing SC. The Relationship of Carotid plaque, Intima Media Thickness (ITM), Resistivity Index (RI) and Pulsatility Index (PI) in Asian- Indian patients with Acute Ischemic Stroke with and without type DM. International Journal of Clinical Medicine 2011; 2 (5): 7.

6. Sacco RL, Kasner SE, Broderick JP, Caplan LR, Connors JJ, Culebras A, et al. An Updated Definition of Stroke for the 21st Century: A Statement for Healthcare Professionals from the American Heart association/American Stroke Association. Stroke 2013; 44: 20642089.

7. Putaala J, Metso AJ, Metso TM, Konkola N, Kraemer Y, Haapaniemi E, Kaste M, Tatlisumak T. Analysis of 1008 consecutive patients aged 15 to 49 with first-ever ischemic stroke: the Helsinki young stroke registry. Stroke 2009; 40 (4): 1195-1203.

8. Burn J, Dennis M, Bamford J, Sandercock P, Wade D, Warlow C. Long-Term Risk of Recurrent Stroke after a First-Ever Stroke. The Oxfordshire Community Stroke Project. Stroke 1994; 25: 333-337.

9. Hossain MZ, Ahmed SU, Sarder MH, Dasgupta R, Das A, Sarker RN et al. Analysis of risk factors associated with stroke in young adults: a prospective study. J Dhaka Med Coll 2009; 18: 95-99.

10. Uddin MJ, Mondol BA, Ahmed S, Ullah AA, Jabber MA, Mohammad QD, 'Smoking and ischemic stroke'. Bangladesh Journal of Neuroscience 2008; 24: 50-54.

11. Idicula TT, Waje-Andreassen $U$, Brog J, Naess $\mathrm{H}$. 'Serum albumin in ischemic stroke patients: The Higher the Better'. Cerebrovascular Disease 2009; 28: 13-17.

12. Hannan MA, Rahman MM, Haque A, Ahmed HU. 'Stroke: Seasonal variation and 
association with hypertension'. Bangladesh Medical Research Council 2001; 27 (2): 69-78.

13. Stratton IM, Adler Al, Andrew H, Neil W, Matthews DR, Manley SE, et al. on behalf of the UK ProspectiveDiabetes Study Group.. Association of glycaemia with macrovascular and microvascular complications of type 2 diabetes (UKPDS 35): prospective observational study. BMJ 2000;321: 405-12.

14. Siddique MAN, Nur Z, Mahbub MS, Alam MB, Miah MT. Clinical Presentation and Epidemiology of Stroke -A Study of 100 Cases.J Medicine 2009; 10: 86-89.

15. Karapanayiotides Th, Piechowski-Jozwiak B, van Melle G, Bogousslavsky, J, Devuyst G. Stroke patterns, etiology, and prognosis in patients with diabetes mellitus. Neurology 2004; 62:1558-1562.
16. Nedeltchev K, der Maur TA, Georgiadis D, Arnold M,Caso V, Mattle HP, et al. Ischaemic stroke in young adults: predictors of outcome and Recurrence. J Neurol Neurosurg Psychiatry 2005; 76:191-195.

17. Leoo T, Lindgrenb A, Peterssonc J, von Arbin M. Risk Factors and Treatment at Recurrent Stroke Onset: Results from the Recurrent Stroke Quality and Epidemiology (RESQUE) Study. Cerebrovasc Dis 2008: 25: 254-260.

18. Moroney JT, Bagiella E, Paik MC, Sacco RL, Desmond DW. Risk Factors for Early Recurrence after Ischemic Stroke: The Role of Stroke Syndrome and Subtype. Stroke 1998; 29: 2118-2124.

19. Fu G-R, Yuan W-Q, Du W-L, Yang Z-H, Fu $\mathrm{N}$, Zheng $\mathrm{H}-\mathrm{G}$, et al. Risk Factors Associated with Recurrent Strokes in Young and ElderlyPatients: A Hospital-based Study. International Journal of sGerontology 2015; 9: $63 \mathrm{e} 66$. 